\title{
Mental Health Disorders Status in Bangladesh: A Systematic Review
}

\author{
Anwar Hossain*1, Jinnat Rehena ${ }^{2}$ and Musammat Sultana Razia ${ }^{3}$ \\ ${ }^{1}$ Master of Science in Nursing (Mental Health and Psychiatric Nursing), National Institute of Advanced Nursing Education (NIANER), Bangladesh \\ ${ }^{2}$ Master of Science in Nursing (Adult and Elderly Health Nursing), Mahidol University, Thailand \\ ${ }^{3}$ Master of Science in Nursing (Nursing Management), National Institute of Advanced Nursing Education (NIANER), Bangladesh
}

Submission: April 02, 2018; Published: April 11, 2018

*Corresponding author: Anwar Hossain, Nursing Officer, National Institute of Advanced Nursing Education (NIANER), Bangladesh, Email: bjnd18@gmail.com

\begin{abstract}
Mental disorders constitute a major public health problem globally with higher burden in low and middle-income countries. In Bangladesh, systematically-collected data on mental disorders are scarce and this leaves the extent of the problem not so well defined. We reviewed the literature on mental health disorders in Bangladesh to summarize the available data and identify evidence gaps. Researcher identified relevant literature on mental disorders within Bangladesh published between 2000 and 2016 through a comprehensive search. Relevant information from the selected articles was extracted and presented. Researcher identified 11 articles which met our pre-defined eligibility criteria. The reported prevalence of mental disorders varied from 6.5 to $31.0 \%$ among adults and from 13.4 to $22.9 \%$ among children. Some awareness regarding mental health disorders at all level. There is a negative attitude towards treatment of those affected and treatment is not a priority in health care delivery and No specialization course on psychiatric nursing. The burden of mental disorders is high in Bangladesh, yet a largely unrecognized and under-researched area. So to introduce psychiatric nursing training and by the training, the mental health services will improve in Bangladesh. Further well-designed epidemiological and clinical research are needed.
\end{abstract}

Keywords: Mental health; Mental disorders; Depression; Prevalence; Service

Abbreviations: NIMH: National Institute of Mental Health

\section{Introduction}

Mental disorders constitute a major public health problem and contribute to $13 \%$ of the global burden of disease measured as disability adjusted life years (Mathers 2008). Low and middle income countries have higher burden of mental disorders than economically developed countries Bass et al. [1]. Mental disorders have serious negative effect on survival, and when present with chronic diseases as co-morbid condition, serious mental disorders may reduce life expectancy by about 20 years Colton et al. [2]. Mental disorders are generally not perceived as a health problem and are not priority in the health care delivery. Epidemiological and health system data related to mental disorders are scarce and are not readily available in Bangladesh although a few published articles provide some estimates of different mental disorders. Mental health literacy has received increasing attention as a useful strategy to promote early identification of mental disorders, reduce stigma and enhance help-seeking behaviors. However, despite the abundance of research on mental health literacy interventions, there is the absence of evaluations of current available mental health literacy measures and related psychometrics. This review was conducted to understand the prevailing situation and trends in mental disorders in Bangladesh. This is expected to generate useful insights and may assist health professionals and policy makers in defining the need and planning service delivery models.

\section{Methods}

\section{Search Strategy}

Researcher searched, collected and evaluated literature on mental disorders based on the Preferred Reporting Items for Systematic Reviews and Meta-Analyses. The protocol was chosen from several methodologies and guidelines for the optimal reporting of systematic reviews specifically for quantitative studies. Researcher identified relevant college students' knowledge, beliefs and attitudes about mental disorders based literature through a comprehensive scientific literature search using the data-bases of PubMed, Google Scholar, and the Bangladesh Journals Online. Researcher used the following search terms: "mental disorders, depression, prevalence, service delivery, referral, management, treatment, Bangladesh". 
Researcher combined search terms using Boolean operators to narrow the search results. Researcher carried out a manual search to identify additional articles was carried out based on the bibliographies of the identified published studies ('snowballing'). References and cross-references of the articles were critically studied through manually to find any relevant study missed by the electronic and/or manual search. Additionally, local journals that could not be accessed online were also searched manually. Researcher also retrieved the full-text for the unpublished/gray literature from web side and library of the National Institute of Mental Health (NIMH) Bangladesh. Citations were managed using Endnote version X4.0. A narrative synthesis of the finally selected articles was reported.

\section{Inclusion and Exclusion Criteria}

Researcher included articles which presented;

a) Quantitative outcome data on mental health and mental disorders between developing and developed countries

b) Reported on human participants

c) Were published between 2000 and 20165 and

d) Published in English.

Researcher excluded articles which were:

a) Qualitative studies,

b) Those published as theses/dissertations, and

c) Not in English.

\section{Quality Assessment}

Initially, Researcher screened and evaluated each article individually to decide on its inclusion or exclusion. Articles were further assessed for

(i) The appropriateness and clarity of the research question/objectives/aims $(\mathrm{y} / \mathrm{n})$ and the study design chosen $(\mathrm{y} / \mathrm{n})$,

(ii) Adequate description of study location $(\mathrm{y} / \mathrm{n})$, sample/ participants $(y / n)$, data collection methods $(y / n)$, context of collection and quantitative outcome data presented $(\mathrm{y} / \mathrm{n})$

(iii) Adequacy of measurement and appropriateness of statistical analysis (e.g. the odds ratio, p values and confidence interval) $(\mathrm{y} / \mathrm{n})$.

For each article found, titles and abstracts were initially examined to determine whether the selection criteria were met. If an article failed to meet these criteria, the full text article was not retrieved and was excluded.

We categorized the articles and tabulated by

a) Study location

b) Study method: "prevalence/cross-sectional study, case control, cohort, specific population survey and by c) Outcome: "mental disorders, adult prevalence, service delivery/referral pattern/management/treatment". A record of all excluded studies and the reasons for exclusion was documented.

\section{Selection of Literature}

Through the initial search of databases, we identified several articles on mental health as well as mental disorders in Worldwide. After the review of titles and the abstracts we included 11 articles as they were deemed not relevant to the review. Out of the remaining articles, didn't match with criteria. Finally, 10 studies met the inclusion criteria for the review. Most common mental disorders in the selected articles were major anxiety, depression and overall psychiatric disorders.

\section{Overall Results}

Participants were 218 students at Reykjavík University. Prejudice towards mental disorders was rather low among participants. Results revealed that there is a significant inverse relationship between familiarity and prejudice, both having a family member diagnosed with a mental disorder $(\beta=-.150$, $\mathrm{p}<0,05)$ and a friend diagnosed with a mental disorder $(\beta=$ $-.174, \mathrm{p}<0,01$ ), when all other variables had been accounted for Brynjólfsson [3].

Responses were collected from 673 persons with a response rate of $84 \%$. While participants were agreed that particular diseases were mental illnesses, overall knowledge scores were low. Knowledge was higher among those persons who knew someone with a mental illness. Attitude scores were suggestive of stigmatization, with drug abuse and schizophrenia seen in a particularly poor light Youssef et al. [4]. A majority (65\%) of untreated students reported low stigma and positive beliefs about treatment effectiveness, including $42 \%$ who perceived a need for help and $23 \%$ who did not Eisenberg et al. [5]. Results showed high rates of psychiatric medication misuse when compared to rates of medical use. Participants reported believing that the majority of students who use prescription psychotropics do so non-medically. In addition, less-stigmatized attitudes toward mental illness were correlated with both increased beliefs about the treatability of mental illness and increased misuse of psychiatric medications. Conversely, more stigmatized beliefs were associated with negative views toward psychiatric medication, as well as decreased likelihood of abuse Stone et al. [6]. The undergraduate medical student population had significant shortcomings in knowledge and attitude pertaining to psychiatric disorders, more glaring in the initial years of education. A comparatively positive opinion was obtained regarding psychiatry as a subject and psychiatrists as professionals, which may reflect the changing trends and concepts, both in society and medical community Aruna et al. [7]. Significant differences were found between students who had experienced mental illness and those who had not. Differences were also found between students with friends who suffered from mental health problems and those who did 
not Granados-Gámez et al. [8]. Nurses' attitudes towards people with mental illness were generally positive. The nurses mostly reported willingness to help and feelings of concern and sympathy towards these patients. However, younger nurses or those without additional mental health training expressed a fear of patients Ihalainen-Tamlander et al. [9]. Respondents commonly perceived people with schizophrenia, alcoholism and drug addiction as unpredictable and dangerous. The two latter conditions were also viewed as self-inflicted. People with any of the seven disorders were perceived as hard to talk with. Opinions about effects of treatment and prognosis suggested reasonable knowledge. About half the respondents reported knowing someone with a mental illness Crisp et al. [10]. Significant differences were found between students who had experienced mental illness and those who had not. Differences were also found between students with friends who suffered from mental health problems and those who did not Granados-Gámez et al. [8]. Researcher located 401 studies that include 69 knowledge measures (14 validated), 111 stigma measures (65 validated), and 35 help-seeking related measures (10 validated). Knowledge measures mainly investigated the ability of illness identification, and factual knowledge of mental disorders such as terminology, etiology, diagnosis, prognosis, and consequences. Stigma measures include those focused on stigma against mental illness or the mentally ill; self-stigma; experienced stigma; and stigma against mental health treatment and help-seeking. Help-seeking measures included those of helpseeking attitudes, intentions to seek help, and actual help-seeking behaviors Wei et al. [11]. The overall prevalence of psychiatric disorders in this rural area was $16.5 \%$. Depressive disorders and anxiety disorders constituted about one-half and one-third of the total cases, respectively. A significantly higher prevalence of mental disorders was found in the economically poor respondents, those over 45 years of age, and women from large families Hosain et al. [12]. Researcher located 401 studies that include 69 knowledge measures (14 validated), 111 stigma measures (65 validated), and 35 help-seeking related measures (10 validated). Knowledge measures mainly investigated the ability of illness identification, and factual knowledge of mental disorders such as terminology, etiology, diagnosis, prognosis, and consequences. Stigma measures include those focused-on stigmas against mental illness or the mentally ill; self-stigma; experienced stigma; and stigma against mental health treatment and help-seeking. Help-seeking measures included those of help-seeking attitudes, intentions to seek help, and actual help-seeking behaviors Wei et al. [11].

\section{Discussion}

Many mental health disorders emerge in late childhood and early adolescence and contribute to the burden of these disorders among young people and later in life [13]. I systematically reviewed literature published up to December 2015 to identify systematic reviews on mental health interventions in adolescent population. A total of 11 systematic reviews were included but searched lots of different type of literature. We classified the included reviews into the following categories for reporting the findings. I found only a limited number of published studies on college students' knowledge, beliefs and attitudes about mental health. It is worthwhile to mention some of the limitations of the review. Data from the selected articles are not comparable due to differences in settings, different assessment tools and the different thresholds used to determine the psychiatric disorders. Therefore, the various result could not summarize for estimation of available resource the over time. In the study was to get a better understanding of which variables affect attitude towards mental disorders. Of special interest was to explore how familiarity with mental disorders affected attitude. Students of Reykjavík University, Prejudice towards mental disorders was rather low among participants. Results revealed that there is a significant inverse relationship between familiarity and prejudice. These findings further address the issue individuals with mental disorders are facing, stigmatization and social distancing Brynjólfsson [3]. Mental illness is a significant contributor to global disease burden and this is expected to increase over the coming decades. Traditionally mental illness has not been well understood by the general public, resulting in poor attitudes towards persons with mental illness and stigmatization. This study was to assess knowledge and attitudes towards mental illness among college students within the English-speaking Caribbean. Overall knowledge scores were low. Knowledge was higher among those persons who knew someone with a mental illness. Attitude scores were suggestive of stigmatization, with drug abuse and schizophrenia seen in a particularly poor light Youssef et al. [4]. This study estimated attitudes and beliefs about treatment in a national sample of college students with untreated mental health problems. A majority (65\%) of untreated students reported low stigma and positive beliefs about treatment effectiveness, including $42 \%$ who perceived a need for help and $23 \%$ who did not Eisenberg et al. [5]. Mental illness stigma remains a significant barrier to treatment. Participants reported believing that the majority of students who use prescription psychotropics do so non-medically. In addition, less-stigmatized attitudes toward mental illness were correlated with both increased beliefs about the treatability of mental illness and increased misuse of psychiatric medications. Conversely, more stigmatized beliefs were associated with negative views toward psychiatric medication, as well as decreased likelihood of abuse Stone et al. [6]. This study aims at evaluating the perception, knowledge, and attitude toward psychiatric disorders. A comparatively positive opinion was obtained regarding psychiatry as a subject and psychiatrists as professionals, which may reflect the changing trends and concepts, both in society and medical community Aruna et al. [7].

\section{Conclusion}

This review showed that researches on mental disorders are not at satisfactory level in Bangladesh given the magnitude of the problem. To improvise the mental health services, not only in Bangladesh, further well-designed epidemiological and clinical research is needed. Public education and awareness campaigns 
on mental health conditions may be undertaken to restructure misconceptions. The widespread educational campaigns need to be implemented across the region, designed to both increase knowledge and beliefs about mental illness and come in change in attitude about mental health and reduce discrimination towards persons suffering with mental illness.

\section{References}

1. Bass JK, Bornemann TH, Burkey M, Chehil S, Chen L, et al. (2012) A United Nations General Assembly Special Session for mental, neurological, and substance use disorders: the time has come. PLoS Med 9(1): e1001159.

2. Colton CW, Manderscheid RW (2006) Congruencies in increased mortality rates, years of potential life lost, and cause of death among public mental health clients in eight states. Prev Chronic Dis 3(2): A42.

3. Brynjólfsson S (2016) Attitudes and beliefs towards mental disorders.

4. Youssef FF, Bachew R, Bodie D, Leach R, Morris K, et al. (2014) Knowledge and attitudes towards mental illness among college students: Insights into the wider English-speaking Caribbean population. Int J Soc Psychiatry 60(1): 47-54

5. Eisenberg D, Speer N, Hunt JB (2012) Attitudes and beliefs about treatment among college students with untreated mental health problems. Psychiatr Serv 63(7): 711-713.

6. Stone AM, Merlo LJ (2011) Attitudes of college students toward mental illness stigma and the misuse of psychiatric medications. J Clin Psychiatry 72(2): 134-139.

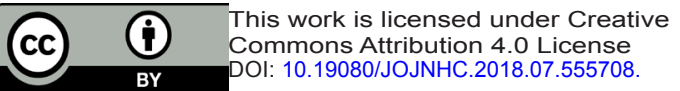

7. Aruna G, Mittal S, Yadiyal MB, Acharya C, Acharya S, et al. (2016) Perception, knowledge, and attitude toward mental disorders and psychiatry among medical undergraduates in Karnataka: A crosssectional study. Indian J Psychiatry 58(1): 70-76.

8. Granados Gámez G, López Rodríguez M, Corral Granados A, Márquez Hernández VV (2016) Attitudes and Beliefs of Nursing Students Toward Mental Disorder: The Significance of Direct Experience With Patients. Perspectives in psychiatric care 53(2): 135-143.

9. Ihalainen Tamlander N, Vähäniemi A, Löyttyniemi E, Suominen T Välimäki M (2016) Stigmatizing attitudes in nurses towards people with mental illness: a cross-sectional study in primary settings in Finland. J Psychiatr Ment Health Nurs 23(6-7): 427-437.

10. Crisp AH, Gelder MG, Rix S, Meltzer HI, Rowlands OJ (2000). Stigmatisation of people with mental illnesses. Br J Psychiatry 177(1): 4-7.

11. Wei Y, Mc Grath PJ, Hayden J, Kutcher S (2015) Mental health literacy measures evaluating knowledge, attitudes and help-seeking: a scoping review. BMC psychiatry 15(1): 291.

12. Hosain GM, Chatterjee N, Ara N, Islam T (2007) Prevalence, pattern and determinants of mental disorders in rural Bangladesh. Public Health 121(1): 18-24.

13. Mathers C (2008) The global burden of disease: 2004 update. World Health Organization, USA.

\section{Your next submission with Juniper Publishers} will reach you the below assets

- Quality Editorial service

- Swift Peer Review

- Reprints availability

- E-prints Service

- Manuscript Podcast for convenient understanding

- Global attainment for your research

- Manuscript accessibility in different formats ( Pdf, E-pub, Full Text, Audio)

- Unceasing customer service

Track the below URL for one-step submission https://juniperpublishers.com/online-submission.php 